\title{
Relation of multiple cranial nerve dysfunction to the Guillain-Barré syndrome
}

\author{
THEODORE L. MUNSAT AND JAMES E. BARNES
}

From the Division of Neurology, Department of Medicine, University of California at Los Angeles, and the
Division of Neurosurgery, Department of Surgery, Ohio State University, Columbus, Ohio, U.S.A.

Multiple cranial nerve dysfunction can occur with primary intracranial processes (neoplasm, basilarvertebral insufficiency, congenital defects, aneurysms, dural vein thrombosis, multiple sclerosis), myopathy or neuromuscular junction disorder (myasthenia gravis, botulism, orbital 'myositis', ocular myopathy), and as a manifestation of a more systemic disorder (sarcoidosis, endocrinopathy, connective tissue disease, diphtheria, heavy metal intoxication, nutritional deficiency, diabetes). However, when the clinical syndrome is acute in onset, self limited in course and unaccompanied by evidence of systemic disorder, most of these possibilities become untenable. Multiple sclerosis then becomes the main clinical consideration and this diagnosis can usually be ruled in or out by the clinical findings and a period of observation.

In 1938, Van Bogaert and Maere reported three patients with acute cranial nerve dysfunction that they felt represented a form of the Guillain-Barré syndrome confined to the cranial nerves. Since then several additional case reports have appeared, mainly in the French literature. The existence of such a clinical entity, however, has not been well accepted in the English literature. The controversy over what is and what is not the Guillain-Barré syndrome and whether the eponym should be used at all continues unabated. The clinical aphorism that the Guillain-Barré syndrome is easy to diagnose but impossible to define is as true today as it has been in the past. The diagnosis thus is based on a preponderance of established clinical features (Haymaker and Kernohan, 1949; Guillain, 1953; Baker, 1943; Dempsey, Karnosh, and Gardner, 1947; Duvoisin, 1960), none of which alone is pathognomonic.

It is the purpose of this paper to review the literature pertaining to the existence and significance of a 'cranial nerve form' of the Guillain-Barré syndrome and to present additional case illustrations.

\section{HISTORICAL REVIEW}

At a symposium held in Brussels in 1937, Dr.
Guillain proposed a clinical classification of the Guillain-Barré syndrome based on topographic considerations (Guillain, 1938). He thus divided cases into four basic types: 1 'la forme inférieure', which included patients with involvement of the extremities only; 2 'la forme mixte spinale et mésocéphalique', composed of patients with deficits of both extremities and cranial nerves; 3 'la forme mésocéphalique pure', which comprised a syndrome limited to the cranial nerves; and 4 'une forme de polyradiculonéurite avec troubles mentaux', which included patients with a polyradiculopathy and mentation change. The third category, or cranial nerve form, was based on a personally observed case (Guillain and Kreis, 1937, case II) as well as a case presented by Van Bogaert during the same symposium. Guillain's patient was a 27 -year-old man whose neurological illness was preceded by upper respiratory infection and gastrointestinal complaints. The patient then rapidly developed a syndrome of unilateral cranial neuropathy with involvement of nerves V, VI, and VII, as well as 'mild optic neuritis with retinal venous dilatation and mild papilloedema'. The spinal fluid was xanthochromic with 8 cells and a protein concentration of $150 \mathrm{mg} . \%$. The patient made a rapid and uneventful recovery. This case presents several features which are difficult to evaluate, i.e., the nature of the funduscopic findings, the striking unilaterality of the cranial nerve involvement and the xanthochromic appearance of the spinal fluid with a protein concentration of only $150 \mathrm{mg} . \%$. These features leave the exact nature of this patient's illness in question.

Van Bogaert's patient was subsequently reported with two additional cases in 1938 (Van Bogaert and Maere, 1938). In the introduction to this paper he states the following propositions: 'Since polyneuritis of the limbs can occur without clinical involvement of the cranial nerves, it seems reasonable to ask whether there might also exist a syndrome of bilateral cranial neuropathy without clinical involvement of the limbs.' He then presents three cases which he feels fulfils such a clinical syndrome. In two, upper respiratory infection antedated the 
onset of neurological dysfunction. The third patient was admitted to hospital for a skull fracture and developed cranial nerve symptoms 12 days later. All three had bilateral seventh nerve weakness of a lower motor neurone type. In addition, cases 1 and 2 had pharyngeal weakness and facial hypaesthesia. One patient (case 3) had questionable shortlived weakness of both lower extremities. This is the only patient who showed objective changes in the extremities, although two complained of radicular type pain.

Following these reports additional papers appeared in the European literature presenting cases of a similar syndrome (Massion-Verniory, 1940; Maestro, 1942; Darcourt and Cossa, 1959; Arnould, Tridon, Schmitt, and Guerci, 1960). Although individual variation is present, the case reports demonstrate clinical similarity. The pattern is that of acute onset of multiple cranial neuropathy, frequently following a benign infectious process. Involvement of the extremities, if present at all, is minimal and is limited to paraesthesiae, depressed deep tendon reflexes, and/or mild shortlived paresis. Total external ophthalmoplegia with eyes fixed in the primary position is common while pupillary abnormalities are uncommon. Lower motor neurone involvement of other cranial nerves is frequent. Most commonly involved are cranial nerves VII, IX, and X. The deficit is usually bilateral and symmetrical. Ataxia is occasionally present. The cerebrospinal fluid protein level is frequently elevated with a normal cell count. The course is benign, with full recovery within several weeks the rule. Recurrence and permanent deficit do not occur. Systemic manifestations are rare. Illustrative of these cases is case 1 reported by Massion-Verniory (1940). This patient was a 34-year-old man who, following a mild gastrointestinal syndrome, showed an acute onset of bilateral ophthalmoplegia and bilateral seventh nerve weakness of a lower motor neurone type. The extremities were not involved. Cerebrospinal fluid protein was elevated to $260 \mathrm{mg}$. $\%$. Recovery was rapid and complete.

Although this syndrome appears to be a well accepted clinical entity in the European literature, few American or British authors have discussed the subject. Until 1956, we find only brief reference to the existence of a 'cranial form' of the GuillainBarré syndrome. Although Baker (1943) includes a 'bulbar form' in his classification of types of clinical involvement, he states that 'this type of the illness is almost invariably accompanied by the involvement of other parts of the nervous system', and he does not specifically mention a pure form of cranial nerve involvement. His single illustrative case of the bulbar type is a patient who had considerable weakness of the extremities. In Haymaker and ${ }^{\circ}$ Kernohan's (1949) classic review brief reference is $\mathbb{C}$ made to Guillain and van Bogaert's original reports but once again the presence of a syndrome limited to the cranial nerves is not discussed.

In 1956, Fisher reported three patients in a paper entitled 'An unusual variant of acute idiopathic polyneuritis (syndrome of ophthalmoplegia, ataxia, $\frac{\overline{\mathrm{N}}}{\mathrm{s}}$ and areflexia)'. In reviewing these case histories similarities to the European reports are at once apparent. All three patients had evidence of prior $\overrightarrow{\vec{F}}$ respiratory infection and showed an acute onset of neurological dysfunction. Two patients complained of paraesthesiae. All showed external ophthal- $\overline{\bar{c}}$. moplegia, absent deep tendon reflexes, and ataxia. $\underset{\propto}{2}$ In two, ataxia occurred without sensory deficit. $\frac{a}{2}$ Questionable weakness of the extremities was ${ }^{\infty}$ present in only one patient. The cerebrospinal fluid $\overrightarrow{0}$ protein level was markedly elevated in one of the $\overrightarrow{-}$ two cases in which lumbar puncture was performed. $\stackrel{\omega}{\sigma}$ The course was one of spontaneous remission. As the title of his paper indicates, it was felt that these patients demonstrated a form of the Guillain- $i$ Barré syndrome. Following Fisher's paper additiona cases were reported by Neubert (1958), Hynes (196B, and Smith and Walsh (1957). Ford's text (1966) ज contains a description of a sirnilar patient. Recento Charous and Saxe (1962) reported a patient who alsofits into this clinical category. All of these patients 5 present a similar clinical picture and all authes accept a relationship to the Guillain-Barré syndrome. $\overrightarrow{0}$ Illustrative of these reports is case 1 of Smith a Walsh (1957). This was a 38-year-old man, who seven. days after an upper respiratory infection, awokeo with vertigo, diplopia, and ataxia. Three days later examination revealed total bilateral ophthalmo-Ō plegia with eyes fixed in the primary position, normalo pupils, bilateral lower motor neurone seventh nerve? weakness, ataxic gait, and depressed deep tendon $\overrightarrow{\overrightarrow{\vec{O}}}$ reflexes. No paresis of the extremities was present. 3 Spinal fluid obtained on the thirteenth day of the? neurological illness showed a protein level of $72 \stackrel{\mathrm{D}_{\text {. }}}{\mathrm{m}}$ $\mathrm{mg} . \%$. By the 60 th day almost complete resolution had occurred.

\section{CASE REPORTS}

The following case reports are presented additional examples of this clinical entity.

CASE 1 A 5-year-old boy was admitted to the U.S. Naval Hospital, Great Lakes, Illinois, on 18 Novembero 1961, complaining of diplopia. The patient was born of $\mathrm{a}$. normal delivery without perinatal difficulty. Development was normal. He had had the usual full immunization without sequelae. He had had no significant past illnesses. His family history gave no evidence of neuromuscular disorder. 
On 25 October 1961, the patient's sister developed an upper respiratory infection with sore throat and fever. Examination revealed a follicular tonsilitis. She developed a fine maculo-papular rash which later desquamated. Throat culture revealed beta haemolytic streptococci and she was treated with penicillin with good results. Eight days after the onset of his sister's illness, the patient developed coryza, conjunctivitis, sore throat, and fever to $102^{\circ} \mathrm{F}$. That evening he developed an extensive macular rash which disappeared in 24 hours. He was placed on tetracycline by mouth. Over the next 72 hours he gradually returned to an asymptomatic state. On the morning of 1 November, eight days after the onset of his upper respiratory syndrome, he awoke complaining of diplopia. Examination at this time revealed ataxic gait, right-sided ptosis, and right 'esotropia'. Deep tendon reflexes and peripheral strength were described as normal. Throat culture revealed beta haemolytic streptococci in pure culture. Lumbar puncture was 'unremarkable'. Over the next few days the patient remained systemically well, but was noted to have progressive bilateral ophthalmoplegia and ataxia. At no time did he develop weakness of the extremities, sensory complaints, or sphincter dysfunction. Because of these'symptoms he was transferred to the U.S. Naval Hospital, Great Lakes, Illinois.

Examination on admission revealed a thin, but welldeveloped child in no distress. He did not appear systemically ill. He was alert and intelligent, with no evidence of organic mental dysfunction. Vital signs were within normal limits. The general medical examination was unremarkable. He had an ataxic gait. The Romberg test was negative. Ophthalmoscopic examination revealed normal fundi. The pupils were $3 \mathrm{~mm}$. bilaterally and reacted normally. Marked ptosis was present on both sides. There was complete bilateral external ophthalmoplegia with the eyes fixed in the primary position. No voluntary eye movement was possible and no reflex eye movement could be elicited with rapid head turning. A mild, bilateral, lower motor neurone type of facial paresis was present. The rest of the cranial nerves were unremarkable. Motor examination showed no atrophy, fasciculations, or paresis. Finger-to-nose and heel-to-knee testing were carried out normally. Rapid, rhythmic, alternating movements were unimpaired. There was no past-pointing or rebound. There was, however, generalized deep tendon areflexia. Superficial, deep, and discriminative sensory modalities were intact.

The following laboratory studies were within normal limits: complete blood count, urine analysis, serum protein-bound iodine, skull and chest films, and electroencephalogram. Sedimentation rate was $20 \mathrm{~mm}$. per hour. Antistreptolysin $\mathrm{O}$ titre was 50 Todd units. Lumbar puncture revealed clear fluid with an opening pressure of $80 \mathrm{~mm}$. of spinal fluid. There were 5 lymphocytes per c.mm. The protein was $76 \mathrm{mg} . \%$ and the sugar was $80 \mathrm{mg} . \%$. Tensilon tests on two occasions resulted in no improvement in the degree of ophthalmoplegia. His hospital course was marked by no change in his neurological status. During the last seven days of his period in hospital he was given a trial of prednisone, $10 \mathrm{mg}$. four times a day, without benefit. Improvement in ocular motility and gait began two days after discharge, which was approximately one month after the onset of his neurological disorder. Over the following seven days he gradually became asymptomatic. Neurological examination was within normal limits except for persisting generalized areflexia.

CASE 2 A 20-year-old man was admitted for the first time to the Neurology Service, U.C.L.A. Medical Center, on 4 December 1960. Five weeks before admission the patient noted the onset of blurred and 'jiggly' vision. Four days later ataxic gait and right facial weakness appeared and he began to complain of diplopia. Before the onset of these neurological complaints he was systemically well and gave no evidence of infection.

Abnormal physical findings were confined to the nervous system. There was mild ataxia and unsteadiness in turning. The Romberg test was negative. Visual acuity was normal, the fundi were benign, and no nystagmus was present. There was complete absence of lateral eye movements, both reflex and voluntary. Conjugate vertical movements were normally executed. Pupillary function was normal. There was bilateral seventh nerve weakness of a lower motor neurone type, somewhat greater on the right. The remainder of the cranial nerves were intact. There was no weakness of trunk or musculature of the extremities. No cerebellar deficit was demonstrable in the limbs. The reflexes were normally active. Sensory examination was unremarkable.

Routine laboratory studies of blood and urine were unrevealing. A Tensilon test was negative. An electroencephalogram was mildly abnormal with non-focal, paroxysmal, 5-7 c.p.s. activity accentuated by hyperventilation. Lumbar puncture revealed an opening pressure of $92 \mathrm{~mm}$. of clear spinal fluid, no cells, and a protein concentration of $50 \cdot 8 \mathrm{mg} . \%$. Cerebrospinal fluid colloidal gold test was 0111100000 . Skull films were normal.

A few days after admission, he began to show spontaneous and dramatic improvement. The ataxic gait disappeared, facial weakness cleared, and the extraocular muscle palsy began to improve. During the recovery phase a transient internuclear ophthalmoplegia was noted. Five months after the onset of neurological difficulty he was asymptomatic with a normal neurological examination. Two and one-half years after onset he has continued to be asymptomatic with no evidence of recurrent nervous system disorder.

CASE 3 A 14-month-old girl was admitted to the U.S. Naval Hospital, Great Lakes, Illionois, because of difficulty in swallowing. The child had an uneventful perinatal course and past history. Two weeks before admission she had a short illness characterized by fever and submandibular swelling which was diagnosed as 'mumps'. She rapidly returned to an asymptomatic state and remained well until one week before admission when she developed a progressive syndrome characterized by irritability, unsteady gait, hoarse cry, and dysphagia with aspiration and nasal regurgitation of fluids.

Abnormal findings were confined to the nervous system. The child preferred to lie quietly in bed resisting any attempted movements. When urged to sit or walk marked 
titubation and ataxia were present. Moderate symmetrical dysmetria was present in all extremities. Cranial nerve deficit was limited to IX and X. There was moderate pharyngeal and palatal paresis, a low-pitched, hoarse voice, and dysphagia. Fluids were frequently regurgitated through the nose. The deep tendon reflexes were absent. Hypotonia was present throughout. Moderate weakness of neck flexors was present but otherwise no paresis of extremity or axial musculature was apparent. The child reacted normally to pin pricks, touch, and vibrations. Position sense could not be tested.

Routine blood studies were normal. Lumbar puncture on admission revealed an opening pressure of $100 \mathrm{~mm}$. of clear cerebrospinal fluid with 3 lymphocytes per c.mm. The protein was $145 \mathrm{mg} . \%$ and sugar $84 \mathrm{mg} . \%$. Repeat lumbar puncture two weeks later showed 2 lymphocytes and a protein level of $62.5 \mathrm{mg} . \%$. Chest films revealed a mild perihilar infiltration which rapidly cleared. Serum electrolytes were normal. Throat culture revealed normal flora. Tensilon test was negative. During the first few days after admission dysphagia and aspiration of liquids increased in severity and tracheotomy was required. Ten days after admission improvement began with gradual resolution of all symptoms and signs. Two months after the onset of her illness she was asymptomatic. Examination at this time revealed mild weakness of the neck flexors without other neurological abnormality.

The following two patients were seen and kindly brought to our attention by Dr. M. Howard Triedman. The case reports are abstracted from discharge summaries. The patients were not seen by the authors but are included because of clinical similarity.

CASE 4 A 40-year-old woman was admitted to the U.S. Naval Hospital, Chelsea, Massachusetts, on 12 December 1961, with the diagnosis of 'peripheral neuritis'. Ten days after influenza immunization she noted the onset of paraesthesiae in both hands, dysarthria, and dysphagia with nasal regurgitation. Examination showed normal vital signs. Gait was normal. There was paresis of conjugate upward gaze while conjugate downward gaze was preserved. Diplopia and unilateral nystagmus of the right eye appeared on right lateral gaze. There was mild seventh nerve weakness bilaterally. Pharyngeal motor activity was impaired. Sensory examination was intact. No paresis or cerebellar deficit was present in the extremities. The reflexes were markedly hypoactive to absent. Routine laboratory studies, skull radiographs, and lumbar puncture showed no abnormalities. Her subsequent course was characterized by rapid and progressive resolution of the neurological deficit.

CASE 5 A 24-year-old man was admitted to the U.S. Naval Hospital, Chelsea, Massachusetts, on 6 February 1962, because of diplopia and paraesthesiae. The patient had been in excellent health until two weeks before admission when he noted the onset of a mild upper respiratory infection which cleared without specific therapy. Shortly thereafter he noted paraesthesiae in all extremities and diplopia which was soon followed by the rapid onset of dysphonia, dysphagia, and nasal regurgita- $\bar{z}$ tion.

Examination showed normal vital signs. The pharynx was injected. Gait was normal. Pupillary function was intact. Extraocular movements were impaired bilaterally $\overline{0}$ in all directions of gaze in a non-specific and non- $\circlearrowright$ conjugate fashion. There was suggestive facial weakness.

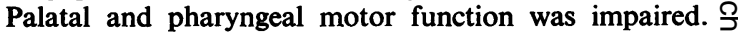
Pin and touch perception were decreased in the feet and hands. Other sensory modalities were intact. There was no paresis or cerebellar deficit in the extremities. The reflexes were equal and normally active. Laboratory $\stackrel{5}{9}$ studies, including lumbar puncture, were unremarkable. $\bar{O}$ His course was one of progressive and rapid improvement $\frac{C}{O}$ and he was discharged to full active duty.

In considering the clinical features common to $\bigcirc$ these five cases there is a striking similarity to the Guillain-Barré syndrome in its classical form (Hay- $\vec{a}$ maker and Kernohan, 1949; Guillain, 1953; Baker, $\vec{\overrightarrow{ }}$ 1943; Dempsey et al., 1947; Duvoisin, 1960). The $\vec{\sigma}$ only significant difference is that the neurological difficulty was confined primarily to the cranial nerves. Thus, in three of the patients the onset of neurolo- in gical dysfunction was preceded by an infectious in process and in another by influenza immunizatio $\widehat{\Phi}_{4}$ In all cases the syndrome was acute in onset and sees limited in course. Evidence of systemic toxicity w宛음 lacking. The cerebrospinal fluid protein level wa elevated in two cases, with a normal cell count in âj $>$ five. Some suggestion of involvement of the extrems ties was present, however, in the form of paraes thesiae (cases 4,5 ) and absent deep tendon reflex (cases $1,3,4)$. The ataxic gait, noted in three patients, occurred in the absence of objective sensory deficit and was felt to be cerebellar in origin. The basic aetiology was not determined.

\section{DISCUSSION}

A few features of this syndrome deserve special 3 comment. Ataxic gait and dysmetria of the extremities are frequently present and occasionally quite severe. Ataxia is also occasionally a prominent finding in the classical form of the Guillain-Barré syndrome (Haymaker and Kernohan, 1949; Fisher, 1956; Martin, 1960) and may occur early in the clinical course or even antedate the onset of involve- $\stackrel{0}{0}$ ment of the extremities (Spector, 1942; Fau and $₹$ Chateau, 1957). It is usually associated with impair-음 ment of deep sensory modalities, and in these cases $D$ is explicable on this basis. Thus the term 'pseudotabetic' is frequently used to describe this clinical aspect. Occasionally, however, marked ataxia and dysmetria occur in the absence of clinical posterior $N$ column loss (Guillain, 1953; Fisher, 1956; Smith and N్ట Walsh, 1957; Martin, 1960; Spector, 1942; Schorder, ত 
1949-1950). This suggests parenchymatous cerebellar damage or involvement of cerebellar pathways in the brain-stem. No pathological evidence is available which demonstrates significant parenchymatous cerebellar changes in the Guillain-Barré syndrome. In fact, in patients demonstrating ataxia without sensory loss the few available reports have demonstrated an absence of cerebellar changes (Martin, 1960; Schorder, 1949-1950; Richter, 1962). More pathological evidence is available to support a brain-stem aetiology. In spite of the reluctance of many to accept intramedullary involvement in the Guillain-Barré syndrome, evidence that such does occasionally occur is available in the literature (Haymaker and Kernohan, 1949; Baker, 1943; Schorder, 1949-1950; Richter, 1962; Strauss and Rabiner, 1930; Polan and Baker, 1942; Shaskan, Teitelbaum, and Stevenson, 1940; Schneider, 1934; Gilpin, Moersch, and Kernohan, 1936; Von Hagen and Baker, 1953; Lowenberg and Foster, 1945). An alternate explanation for ataxia without sensory loss has been proposed by Schorder (1949-1950) and Richter (1962), who present pathological evidence of marked spinocerebellar degeneration in the spinal cord.

Another feature of these cases that deserves comment is the interesting type of ophthalmoplegia that occurs. The presence of total ophthalmoplegia with sparing of pupillary responses, and conjugate and dysconjugate supranuclear gaze palsies as the ophthalmoplegia resolves, suggests interruption of the brain-stem gaze pathways. This aspect has been noted and discussed by Fisher (1956, and 1962, personal communication). Other clinical features, however, support a peripheral mechanism. These include the occurence of eye muscle palsies in the distribution of a specific cranial nerve, the fact that other cranial nerve involvement is of a lower motor neurone type, and the observation that anatomically adjacent motor and sensory pathways in the brain-stem are spared. In addition, the preponderance of pathological information supports a peripheral mechanism (Haymaker and Kernohan, 1949; Baker, 1943; Munch-Petersen and Reske-Nielsen, 1962). We must also consider the possibility that both peripheral and intramedullary mechanisms are operative, giving a mixed clinical picture.

We believe that many cases which demonstrate the syndrome of benign cranial nerve dysfunction should be considered within the scope of the GuillainBarré syndrome for the following reasons: (1) The clinical course and laboratory findings are identical to those described for the Guillain-Barré syndrome in the classical form (Haymaker and Kernohan, 1949; Guillain, 1953; Baker, 1943; Dempsey et al., 1947; Duvoisin, 1960); (2) since cranial neuropathy can pre- cede the onset of weakness of the extremities (Haymaker and Kernohan, 1949, cases 15, 22, 26, 27; Fau and Chateau, 1957, case 4; Chusid and Marquardt, 1945, case 4; Dempsey et al., 1947, case 1, 4; Boshes and Sherman, 1953, case 4) or comprise the main clinical deficit (Baker, 1943, cases 5, 9, 17, 19), it seems reasonable that cranial nerve deficit alone may occur; (3) a graded continuum of neurological involvement can be demonstrated from a pure cranial form (van Bogaert and Maere, 1938, case 1; Massion-Verniory, 1940, case 1; Ford, 1960; Maestro, 1942, cases 1, 2) through a cranial form with subjective involvement of the extremities (van Bogaert and Maere, 1938, cases 2, 3; Neubert, 1958, Smith and Walsh, 1957, cases 1,2) to cranial involvement with minimal objective extremity deficit (Darcourt and Cossa, 1959, Massion-Verniory, 1940, case 2; Chusid and Marquardt, 1945, case 2). The use of the eponym 'Fisher syndrome' (Hynes, 1961; Smith and Walsh, 1957) is thus unwarranted on both historical and clinical grounds.

The diagnosis of Guillain-Barré syndrome does not, and should not, imply any exact aetiological or pathological knowledge, but rather states that the patient fits into a clinical syndrome which has certain common physical findings and prognostic implications. Thus attempts to limit the disorder on arbitrary pathological (Merritt, 1959), clinical (Osler and Sidell, 1960), or historical (Osler and Sidell, 1960) grounds contributes little toward the understanding of basic underlying mechanisms and assumes a body of knowledge which is not yet available. It would be more reasonable to consider first the disorder in all of its possible ramifications and then attach more exact diagnostic criteria as they become available. Such an approach has already provided an insight into the aetiological mechanism (Miglets, Bartlett, Arbesman, and Loeser, 1960; Wells, James, and Evans, 1959).

\section{SUMMARY}

The syndrome of multiple cranial nerve dysfunction and its relation to the Guillain-Barre syndrome is discussed. The pertinent literature is reviewed. Additional case reports are presented.

The authors are indebted to M. Howard Triedman, M.D., for supplying cases 4 and 5 . The greater part of this paper was written while the authors were at the U.S. Naval Hospital, Great Lakes, Illinois.

\section{REFERENCES}

Arnould, G., Tridon, P., Schmitt, J., and Guerci, O. (1960). Polyradiculonévrite aiguë curable à forme ophtalmoplégique. Rev. Oto-neuro-ophtal., 32, 425-428.

Baker, A. B. (1943). Guillain-Barré's disease (encephalomyeloradiculitis): a review of 33 cases. J.-Lancet, 63, 384-398. 
Boshes, B., and Sherman, I. C. (1953). Variability of the course of the Guillain-Barre syndrome. Neurology (Minneap.), 3, 789-799.

Charous, D. I., and Saxe, B. I. (1962). The Landry-Guillain-Barré syndrome: report of an unusual case, with a comment on Bell's palsy. New Engl. J. Med., 267, 1334-1338.

Chusid, J. G., and Marquardt, G. H. (1945). Acute infectious polyneuritis (Guillain-Barré type). Ann. intern. Med., 23, 852-859.

Darcourt, G., and Cossa, P. (1959). Syndrome de Guillain-Barré avec ophtalmoplégie extrinsèque bilatérale et ataxie aiguë. Rev. Oto-neuro-ophtal., 31, 416-418.

Dempsey, W. S., Karnosh, L. J., and Gardner, W. J. (1947). GuillainBarré Syndrome. Cleveland Clin. Quart., 14, 206-217.

Duvoisin, R. C. (1960). Polyneuritis: clinical review of 23 cases of Landry-Guillain-Barré syndrome. U.S. armed Forces med., J., 11, 1294-1306.

Fau, R., and Chateau, R. (1957). Les formes atypiques de la poly. radiculo-névrite de Guillain et Barré: à propos de 5 observations récentes. J. Méd. Lyon, 38, 493-500.

Fisher, M. (1956). An unusual variant of acute idiopathic polyneurotis (syndrome of ophthalmoplegia, ataxia and areflexia). New Engl. J. Med., 255, 57-65.

Ford, F. R. (1960). Diseases of the Nervous System in Infancy, Childhood and Adolescence, pp. 704-705, 4th ed. Thomas, Springfield, Illinois.

Gilpin, S. F., Moersch, F. P., and Kernohan, J. W. (1936). Polyneuritis: a clinical and pathologic study of a special group of cases frequently referred to as instances of neuronitis. Arch. Neurol. Psychiat. (Chic.), 35, 937-963.

Guillain, G. (1938). Les polyradiculonévrites avec dissociation alumbinocytologique et à évolution favorable. (Syndrome de Guillain et Barré.) J. belge Neurol. Psychiat., 38, 323-329.

- (1953). Considerations sur le syndrome de Guillain et Barré. Ann. Méd., 54, 81-149.

hyperalbuminose du liquide céphalo-rachidien sans réaction cellulaire. Paris méd., 2, 224-247.

Haymaker, W., and Kernohan, J. W. (1949). The Landry-GuillainBarré syndrome: a clinicopathologic report of 50 fatal cases and a critique of the literature. Medicine (Baltimore), 28, 59-141.

Hynes, E. A. (1961). Syndrome of Fisher: ophthalmoplegia, ataxia, and areflexia. Amer.J. Ophthal., 51, 701-704.

Lowenberg, K., and Foster, D. B. (1945). Polyradiculo-neuritis with albuminocytologic dissociation. Arch. Neurol. Psychiat. (Chic.), 53, $185-190$.

Maestro, T. (1942). Poliradiculoneurite con dissociazione albuminocitologica (sindrome di Guillain-Barré) esclusiva dei nervi oculari. Riv. oto-neuro-oftal., 19, 153-173.

Martin, J. J. (1960). Polyradiculonévrites aiguës et subaiguës. I. Formes ataxiques des polyradiculonévrites aiguës et subaiguës (surtout de type Guillain-Barre): étude anatomoclinique. Acta neurol. belg., 60, 1087-1139.
Massion-Verniory, L. (1940). Formes pseudo-myasthéniques, a $Z$ début ophthalmoplégique, du syndrome radiculo-névritique $\stackrel{\mathbb{C}}{\subset}$ de Guillain et Barré. J. belge Neurol. Psychiat., 40, 294-305.

Merritt, H. H. (1959). A Textbook of Neurology, p. 606. 2nd ed. Lea and Febiger, Philadelphia.

Miglets, A. W., Bartlett, W. G., Arbesman, C. S., and Loeser, W. D. (1960). Guillain-Barré syndrome resulting from tetanus anti- $T$ toxin injection: second reported case with immunologic studies. Neurology (Minneap.), 10, 658-661.

Munch-Petersen, C. J., and Reske-Nielsen, E. (1962). Polyneuropathy: report of a case. J. nerv. ment. Dis., 134, 463-469.

Neubert, F. R., (1958). Complete ophthalmoplegia in acute toxic polyneuritis. Brit. J. Ophthal., 42, 632-633.

Osler, L. D., and Sidell, A. D. (1960). The Guillain-Barré syndrome: the need for exact diagnostic criteria. New Engl. J. Med., 262, 964-969.

Polan, C. G., and Baker, A. B. (1942). Encephalo-myelo-radiculitis. J. nerv. ment. Dis., 96, 508-522.

Richter, R. B. (1962). Ataxic form of polyradiculoneuritis (LandryGuillain-Barre syndrome): clinical and pathologic observa- $\varrho$ tions. J. Neuropath. exp. Neurol., 21, 171-184.

Schneider, D. E. (1934). Acute infectious meningo-myeloradiculitis. J. Mt. Sinai Hosp., 1, 173-176.

Schorder, P. (1949-1950). Contribution à létude des formes ataxiques ${ }^{\circ}$ du syndrome de Guillain et Barré. These, Universiłé, Nancy (cited by Martin, 1960).

Shaskan, D., Teitelbaum, H. A., and Stevenson, L. D. (1940). Myeloradiculoneuritis with cell-protein dissociation. Arch. Neurol. Psychiat. (Chic.), 44, 599-610.

Smith, J. L., and Walsh, F. B. (1957). Syndrome of external ophthal-i moplegia, ataxia, and areflexia (Fisher); ocular manifestations $\infty$ in acute idiopathic polyneuritis (Guillain-Barré syndromer. $N$ Arch. Ophthal., 58, 108-114.

Spector, S. (1942). Guillain-Barré syndrome: a case with ataxia as tie $\vec{G}$ initial and most prominent symptom. N.Y. St. J. Med., 1959-1961.

Strauss, I., and Rabiner, A. M. (1930). Myeloradiculitis: a clinieg syndrome, with report of 7 cases. Arch. Neurol. Psychiat. (Chic.), 23, 240-256

Van Bogaert, L., and Maere, M. (1938). Les polyradiculonévriơs crâniennes bilatérales avec dissociation albumino-cytologique्:: formes crâniennes des polyradiculonévrites du type Guillōi et Barré. J. belge Neurol. Psychiat., 38, 275-281.

Von Hagen, K. O., and Baker, R. N. (1953). Infectious neuronitis, present concepts of etiology and treatment. J. Amer. med. Ass., $151,1465-1472$.

Wells, C. E. C., James, W. R. L., and Evans, A. D. (1959). GuillainBarré syndrome and virus influenza A (Asian strain): report of two fatal cases during the 1957 epidemic in Wales. Arch. Neurol. Psychiat. (Chic.), 81, 699-705. 